\title{
Surgical Treatment for Digestive Cancer
}

\author{
Current Issues - Colon Cancer
}

Kiyotaka Okuno

Division of Colorectal Surgery, Department of Surgery, Kinki University School of Medicine, Osaka-Sayama, Japan

\section{Key Words}

Colon cancer · Colonic resection · Lymphadenectomy, D3

\begin{abstract}
Background: Due to the westernization of the diet in Japan, the incidence of colorectal cancer has increased 4.5 times in the last 25 years. In this review, the recent results of surgical treatment for colonic cancer and the future perspectives in Japan are described. Materials and Methods: A multi-institutional registry of large bowel cancer in Japan of $10,809 \mathrm{pa}-$ tients with colonic cancer treated from 1991 to 1994 was investigated. The data have been published in the Guidelines of the Japanese Society for Cancer of the Colon and Rectum (2005). Regarding laparoscopic surgery, 1,495 patients with colon cancer were examined in a multicenter study between April 1993 and August 2002. Results: Radical resection with a curative intent is appropriate for $83-99 \%$ of the patients with stage I-III localized colon carcinoma. Adequate lymphadenectomy, including paracolic, intermediate and principal node dissection (D3 lymphadenectomy), is of critical importance for both the accurate staging and local control of the disease. This treatment protocol has now been accepted as a 'standard' operation by Japanese colorectal surgeons. For patients undergoing a curative resection for colon cancer, the 5-year survival rates vary between 62 (stage III) and 91\% (stage I). Adjuvant chemotherapy using 5-FU/leucovorin or oral compounds is commonly administered to patients with stage III disease. Laparoscopic surgery for colonic can-
\end{abstract}

cer yielded a comparable oncological outcome to that reported for conventional open surgery in the Japanese registry for all disease stages. Conclusion: Radical resection with a D3 lymphadenectomy provided satisfactory 5-year survival for patients with stage I-III colon cancer in Japan. However, the survival of patients with stage IV disease is still unsatisfactory (only a $14 \% 5$-year survival). Any further improvements depend on both identifying such patients at an earlier stage as well as developing new and effective treatment modalities.

Copyright $\odot 2007$ S. Karger AG, Basel

\section{Introduction}

Colorectal cancer is a significant health problem in Japan. In 1998 the annual age-adjusted colon cancer incidence per 100,000 individuals in Japan was 42.3 for males and 24.4 for females, and these rates have increased 3.2 times over those reported in 1975 (10.9 for males, 9.7 for females), and they are continuing to increase [1]. In 2001 colorectal cancer was the fourth leading cause of cancer death in men and the second leading cause in women, and it is anticipated to become the leading cause of cancer death in Japan by 2015 due to environmental factors and the changing dietary habits of Japanese people, which are increasingly becoming similar to those of Western countries [2].

\section{KARGER}

Fax +41613061234 E-Mail karger@karger.ch www.karger.com
(C) 2007 S. Karger AG, Basel

0253-4886/07/0242-0108\$23.50/0

Accessible online at:

www.karger.com/dsu
Kiyotaka Okuno

377-2 Ohno-higashi

Osaka-Sayama 589-8511 (Japan)

Tel. +81 72366 0221, ext. 3615, Fax +81 723677771

E-Mail okuno@surg.med.kindai.ac.jp 
Fig. 1. Extent of resection for carcinoma of the colon. $\mathrm{T}=$ Tumor.
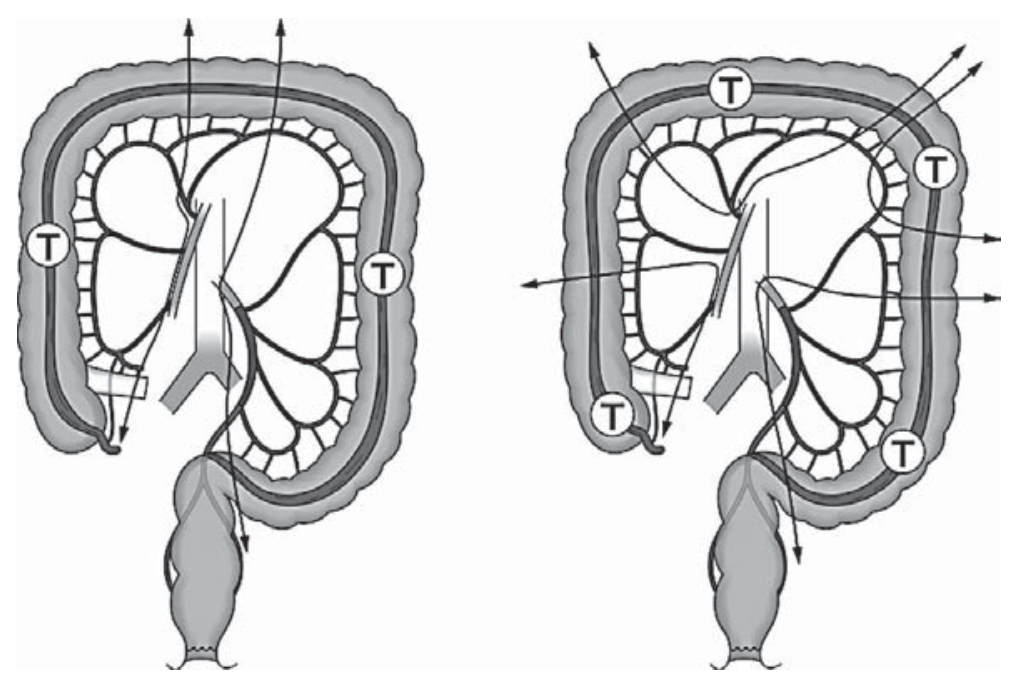

\section{Principles of Resection}

The principle objective of resection for colon carcinoma is to remove the primary tumor along with its lymphovascular supply. Since the lymphatics of the colon accompany the main arterial supply, the length of the resected bowel depends on which vessels supply the segment involved in the cancer [3]. Before 2005, the Japanese General Rules for Clinical and Pathologic Studies on Cancer of the Colon and Rectum (JGR) recommended that a colectomy should be performed with at least $5-$ to $10-\mathrm{cm}$ long proximal and distal margins, and that the regional arterial blood supply should be taken at its origin, thus assuring an adequate mesenteric resection. In the new version of these rules (2006), the cut edge of the bowel is strictly standardized with careful attention being paid to the main arterial supply of the tumor [4].

Lesions of the cecum, ascending colon, and hepatic flexure are usually treated by a right hemicolectomy, because the blood supply to this area comes from the ileocolic and right colic arteries. Figure 1 also shows the extent of a resection for carcinomas of the designated lesions. A left partial colectomy is the preferred operation for tumors involving the distal transverse colon, splenic flexure, and descending colon. In addition, a sigmoidectomy is the standard operation for sigmoid colon cancer.

Surgical Treatment for Colon Cancer

\section{Stage-Specific Therapy}

Stage 0 (Tis NO MO) and Stage I (T1-2 NO MO)

Polyps measuring less than $2 \mathrm{~cm}$ in diameter are removed endoscopically because they basically carry no risk of lymph node metastasis. After a polypectomy, the pathologic margins are examined to ensure that they are free of dysplasia. In the case of a positive margin, depth of submucosal invasion of $\geq 1,000 \mu \mathrm{m}$, lymphovascular invasion, or a poorly differentiated histology, an additional surgical resection is recommended because of the risk of local recurrence and metastatic spread. Polyps measuring $>2 \mathrm{~cm}$ in diameter or sessile polyps which could possibly be invasive carcinoma should be removed by surgical resection. In such cases, laparoscopic segmental colectomy is considered to be a good option. The treatment strategy for malignant polyps is summarized in figure 2.

\section{Stage I and Stage II: Localized Colon Carcinoma}

(T Any, No Mo)

The majority of patients with stage I and II colon cancer can be successfully treated by surgical resection. It is recommended that patients demonstrating a depth of invasion of $\mathrm{T} 3$ or more undergo adequate colonic resection with a D3 lymph node dissection according to the Japanese guidelines [5]. D3 means complete dissection of the regional lymph nodes including the paracolic, intermediate and the principal lymph nodes (fig. 3).

Dig Surg 2007;24:108-114 
Fig. 2. Treatment strategy for endoscopically resected malignant polyps, according to the Japanese Guidelines for Colorectal Cancer [5] with slight modifications.

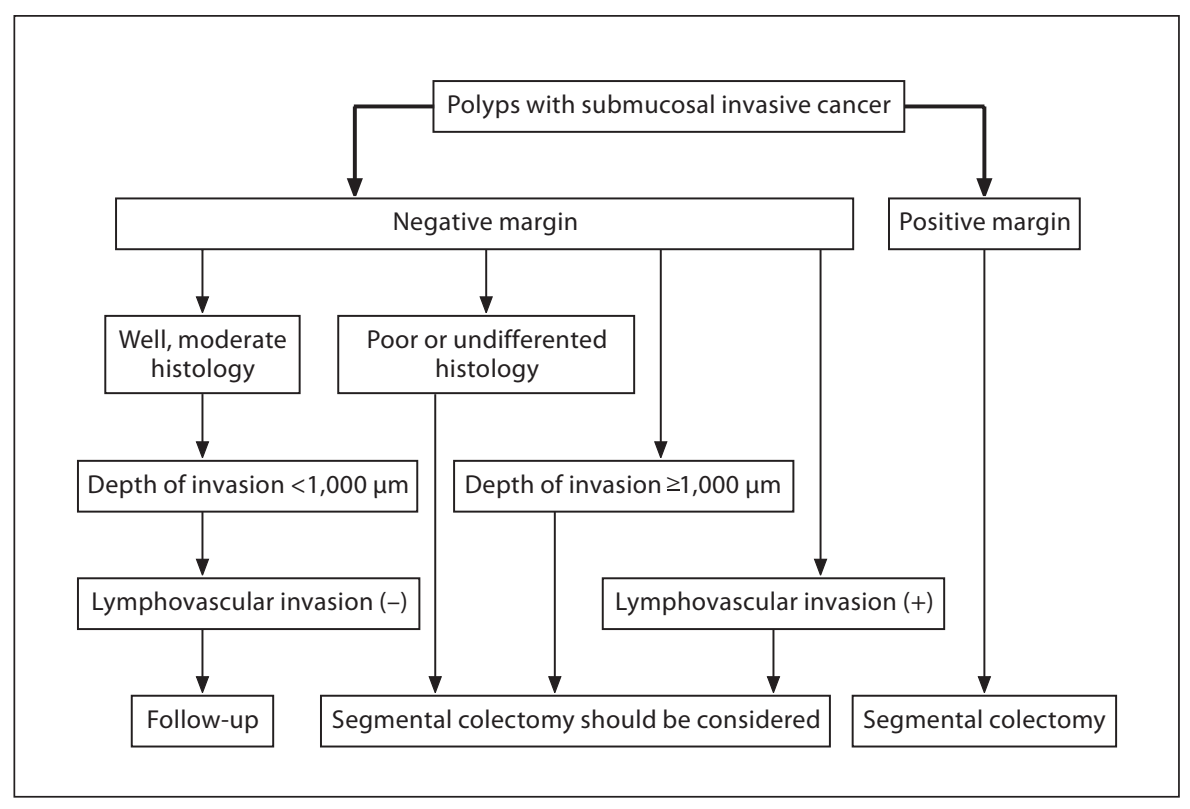

Stage III: Lymph Node Metastasis (T Any, N1-3 M0)

Patients with lymph node involvement are at significant risk for both local and distant recurrence, and therefore an adequate colonic resection with a D3 lymph node dissection should be performed. A D3 lymph node dissection contributes not only to the local control of disease but also to accurate staging. Adjuvant chemotherapy is therefore routinely recommended for these patients.

\section{Adjuvant Chemotherapy}

Adjuvant chemotherapy is regarded as a standard treatment for patients with stage III colon cancer; however, the use of chemotherapy after surgery in patients with stage II disease remains controversial. Although 5fluorouracil (5-FU) has been the mainstay of therapy for the last four decades, we have entered into a new era with the development of novel chemotherapy and biological agents. The combination of adjuvant 5-FU, leucovorin (LV), and oxaliplatin has been shown to significantly improve the disease-free survival and it is now considered to be the standard of care for completely resected colon cancer in healthy patients [6-8]. The Japanese Guidelines recommend the use of 5-FU with LV as the standard adjuvant chemotherapy [5]. The availability of oral chemotherapy agents has helped to make administration easier while also helping to avoid the need to use indwelling catheters.

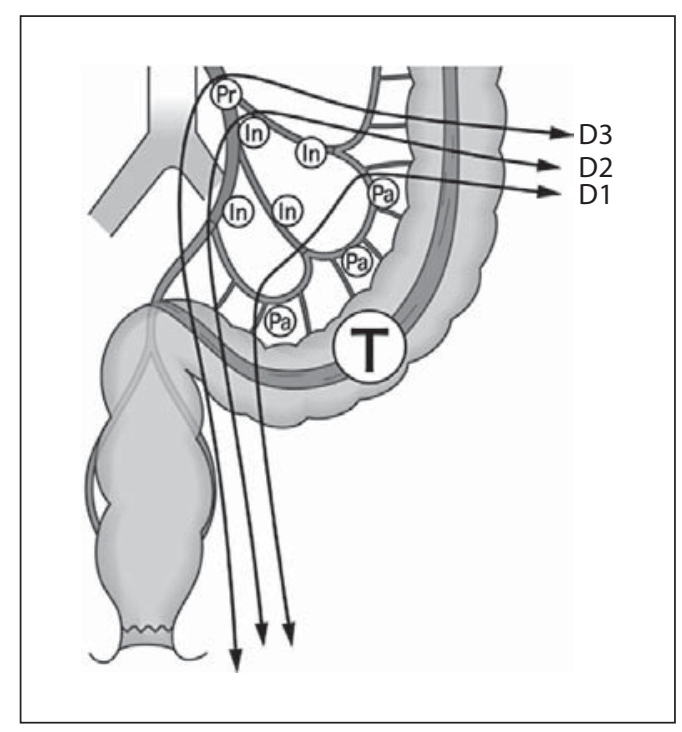

Fig. 3. The extent of dissection of the regional lymph nodes. $\mathrm{Pa}=$ Paracolic lymph node; In = intermediate lymph node; $\mathrm{Pr}=$ principal lymph node; $\mathrm{T}=$ tumor.

\section{Stage IV: Distant Metastasis (T Any, N Any M1)}

The pattern of distant metastases in stage IV disease is summarized in table 1 . The liver is the most common site of metastasis from colorectal cancer. A surgical resection is the only treatment known to provide a long-term survival and the possibility of a cure in patients with liver metastases. 
Table 1. Synchronous distant metastases in colorectal cancer

\begin{tabular}{lrllllllll}
\hline & Liver & Lung & Peritoneum & & \multicolumn{2}{l}{ Others } & & & \\
\cline { 5 - 8 } & & & & & bone & brain & Virchow & other & total \\
\hline Colon cancer $(15,528)$ & $11.4 \%(1,777)$ & $1.6 \%(242)$ & $6.4 \%(993)$ & & $0.3 \%(44)$ & $0.1 \%(9)$ & $0.1 \%(19)$ & $0.4 \%(64)$ & $0.9 \%(136)$ \\
Rectal cancer $(10,563)$ & $9.5 \%(1,002)$ & $1.7 \%(180)$ & $3.0 \%(314)$ & & $0.3 \%(36)$ & $0.1 \%(8)$ & $0.01 \%(1)$ & $0.5 \%(57)$ & $1.0 \%(102)$ \\
Colorectal cancer $(26,091)$ & $10.7 \%(2,779)$ & $1.6 \%(422)$ & $5.0 \%(1,307)$ & & $0.3 \%(80)$ & $0.1 \%(17)$ & $0.1 \%(20)$ & $0.5 \%(121)$ & $0.9 \%(238)$ \\
\hline
\end{tabular}

From the JSCCR, a multi-institutional registry of large bowel cancer in Japan, 1995-1998.

Table 2. Grading of colorectal liver metastasis (JSCCR, 2006)

\begin{tabular}{|c|c|c|c|}
\hline & H1 & H2 & H3 \\
\cline { 1 - 1 } N0 & A & B & \\
\cline { 1 - 1 } N1 & B & \multicolumn{2}{|c}{} \\
\cline { 1 - 1 } N3 & \multicolumn{2}{|c}{ C } \\
\cline { 1 - 1 } M1 & & & \\
\hline
\end{tabular}

$\mathrm{H} 1=$ Four or fewer metastatic tumors and the largest hepatic tumor $\leq 5 \mathrm{~cm}$.

$\mathrm{H} 2$ = Except H1, H3.

$\mathrm{H} 3=$ Five or more metastatic tumors and the largest hepatic tumor $>5 \mathrm{~cm}$.

Regional node status of the primary tumor:

$\mathrm{N} 0=$ Node-negative.

$\mathrm{N} 1$ = Node-positive, $1-3$.

N2 $=$ Node-positive, 4 or more.

N3 = Node-positive along a major named vascular trunk.

Table 3. Five-year survival depending on the grade of liver metastases

\begin{tabular}{llll}
\hline Grade & $\begin{array}{l}\text { All cases } \\
(473)\end{array}$ & $\begin{array}{l}\text { Resected cases } \\
(378)\end{array}$ & $\begin{array}{l}\text { Unresected cases } \\
(95)\end{array}$ \\
\hline A & $50.3 \%(191)$ & $52.9 \%(177)$ & $14.3 \%(14)$ \\
B & $24.5 \%(161)$ & $29.6 \%(121)$ & $7.7 \%(40)$ \\
C & $6.7 \%(121)$ & $10.4 \%(80)$ & $0 \%(41)$ \\
\hline
\end{tabular}

The remainder of patients with stage IV disease, except for patients with multiple organ metastases, such as to the liver and lung, require a resection for cure. However, almost all patients with stage IV disease cannot be surgically cured and therefore the focus of treatment should be palliation. Many of these patients require colonic cancer resection because of symptoms of hemorrhaging and/or obstruction.

\section{Liver Metastasis}

Liver metastasis is the most common metastatic pattern in colorectal cancer. Synchronous liver metastases are present in $10 \%$ of all patients with colorectal cancer and they occur in more than half of all patients with recurrent disease [5]. Of these, $30 \%$ are potentially resectable for cure. The indications for a hepatic resection include control of the primary site, no signs of disseminated disease, no signs of hepatic node metastases, a technically feasible operation, and an adequate hepatic function reserve of the patient.

Hepatic resection has been associated with a $27-40 \%$ 5 -year survival and confers a survival advantage compared to patients not undergoing resection [9-11]. Kato et al. [12] observed a 5 -year survival rate of $39 \%$ for 585 patients who were resected in a multi-institutional study in Japan. The differences among institutes may be related more to the clinical stages at the time of hepatic resection than the surgeon's skills at the individual institutes. A working group of the Japanese Society for Cancer of the Colon and Rectum (JSCCR) has proposed a new staging system based on the number of lymph node metastases from the primary cancer, the number of liver metastases, and the size of the metastatic nodules (table 2). The new staging system appears to be useful for predicting the prognosis of patients with liver metastases from colorectal cancer (table 3).

\section{Lung Metastasis}

Surgical resection is recommended as the first choice for treatment of pulmonary metastases, and the results of the 5-year survival have been reported to range from 30 to $60 \%$ in recently reported series [13-15]. Candidate selection is based on the number and location of metastases, the absence of diseases other than pulmonary disease, an adequate pulmonary function reserve, and a good overall medical condition [5].

Dig Surg 2007;24:108-114 
Table 4. Five-year survival rates based on the JGR classification (1991-1994)

\begin{tabular}{|c|c|c|c|c|c|c|c|}
\hline & Stage 0 & Stage I & Stage II & Stage IIIa & Stage IIIb & Stage IV & All Stage \\
\hline $\mathrm{C}$ & $90 \%(110)$ & $87 \%$ (149) & $81 \%(252)$ & $69 \%(209)$ & $60 \%(137)$ & $10 \%(225)$ & $64 \%(1,082)$ \\
\hline A & $96 \%(209)$ & $91 \%(257)$ & $84 \%$ (698) & $74 \%$ (398) & $57 \%(254)$ & $14 \%$ (409) & $68 \%(2,225)$ \\
\hline $\mathrm{T}$ & $95 \%(176)$ & $89 \%(199)$ & $83 \%(447)$ & $70 \%(270)$ & $60 \%(143)$ & $10 \%(261)$ & $68 \%(1,496)$ \\
\hline $\mathrm{D}$ & $95 \%(129)$ & $90 \%(151)$ & $83 \%(267)$ & $71 \%(152)$ & $58 \%(67)$ & $19 \%(115)$ & $73 \%(881)$ \\
\hline S & $95 \%(559)$ & $91 \%(1,149)$ & $85 \%(1,373)$ & $81 \%(879)$ & $67 \%(394)$ & $17 \%(781)$ & $75 \%(5,135)$ \\
\hline Colon (C-S) & $95 \%(1,183)$ & $91 \%(1,905)$ & $84 \%(3,037)$ & $76 \%(1,908)$ & $62 \%(995)$ & $14 \%(1,791)$ & $71 \%(10,819)$ \\
\hline
\end{tabular}

Stage IIIa included T3N1M0, T4N0M0 in this JGR classification (6th version, 1998), but T4N0M0 is classified as stage II in the new version (7th version, 2006) according to the UICC TNM classification.

$\mathrm{C}=$ Cecum; $\mathrm{A}=$ ascending colon; $\mathrm{T}=$ transverse colon; $\mathrm{D}=$ descending colon; $\mathrm{S}=$ sigmoid colon.

\section{Results of Surgery for Carcinoma of the Colon (from 1991 to 1994)}

JSCCR collected data from a national registry in Japan and calculated the 5-year survival rate depending on the primary lesion (table 4). The survival rates generally correlate with the extent of lymph node involvement. Internationally, the TNM classification system is widely used for staging. In the TNM classification, node metastases are classified into three grades, from $\mathrm{pN} 0$ to $\mathrm{pN} 2$, based on the number of metastatic nodes. In Japan, the JGR have been used as mentioned earlier. In the JGR before 2005, node metastases were classified into four levels, $\mathrm{n}(-), \mathrm{n} 1(+), \mathrm{n} 2(+)$, and $\mathrm{n} 3(+)$, based on the distribution of the metastatic nodes. This system accurately classifies both the patient distribution and survival rates; however, it is considered to be too complicated. In the new version of JGR (2006), the extent of nodal metastases is classified into four grades: N0, N1, N2 and N3. Grades N0-N2 correlate with the N categories of the TNM classification, and N3 is defined as invasion of the principal node [4]. The JGR also indicates the region that should be dissected, thus making this method well suited for clinical use.

\section{Laparoscopic Resection of Colonic Cancer}

In Japan, laparoscopic surgery for colorectal cancer was first introduced in 1992, and many centers are now performing either laparoscopic or laparoscopically assisted colon resections. To date, many studies have confirmed these methods as resulting in a faster recovery, less pain, shorter hospital stay, and satisfactory shortterm oncologic results. However, the long-term oncolog- ic results of laparoscopic surgery for colorectal cancer still remain unclear.

The Japanese Laparoscopic Surgery Study Group collected the data obtained from 12 main institutes of Japan during the period April 1993 to August 2001. During this period, 1,495 patients underwent a laparoscopic colonic resection. Of the 1,495 patients with colonic cancer, 188 (12.6\%) had postoperative complications including: wound infection in 97 cases (60\%); bowel obstruction in 31 cases (19\%); anastomostic leakage in 22 (14\%), and others. Cancer recurred in 61 (4.3\%) of the 1,411 curatively treated patients; however, no port site recurrence was found. The 5 -year survival rate was $96.6 \%$ for the patients with stage I, $94.8 \%$ for those with stage II, and 79.6\% for those with stage III disease [16].

We cannot compare the current data to those of open surgery series because the findings represent an uncontrolled study. These favorable results of laparoscopic surgery for colon cancer have resulted in this treatment being accepted as a radical operation for potentially curable patients in Japan. However, a randomized prospective trial is necessary in the near future.

\section{Follow-Up and Surveillance}

The optimal way to follow patients who have undergone resection for carcinoma of the colon is a subject worthy of some discussion. The main goal of the follow-up is to improve patient survival by making an early diagnosis of recurrence during the asymptomatic stage when radical surgical treatment is still viable. Other goals of followup are to enable early treatment of other bowel lesions including polyps and metachronous cancers, to solve surgery-related problems in a timely manner, to provide pa- 
Table 5. Comparison between the follow-up guidelines

\begin{tabular}{|c|c|c|c|}
\hline & $\mathrm{JSCCR}^{1}$ & ASCO & ESMO \\
\hline $\begin{array}{l}\text { Physical } \\
\text { examination }\end{array}$ & $\begin{array}{l}\text { Every } 3 \text { months for } 3 \text { years then } \\
\text { every } 6 \text { months up to } 5 \text { years }\end{array}$ & $\begin{array}{l}\text { Every } 3-6 \text { months for } 3 \text { years } \\
\text { then every } 6 \text { months up to } 5 \text { years }\end{array}$ & $\begin{array}{l}\text { Every } 3-6 \text { months for } 3 \text { years } \\
\text { then every } 6-12 \text { months up to } 5 \text { years }\end{array}$ \\
\hline CEA & $\begin{array}{l}\text { Every } 3 \text { months for } 3 \text { years then } \\
\text { every } 6 \text { months up to } 5 \text { years }\end{array}$ & $\begin{array}{l}\text { Every } 3 \text { months for at least } 3 \text { years } \\
\text { (stage II or III) }\end{array}$ & No \\
\hline $\begin{array}{l}\text { Chest X-ray } \\
\text { Chest CT }\end{array}$ & $\begin{array}{l}\text { Every } 6 \text { months for } 5 \text { years (X-ray) } \\
\text { or annually for } 5 \text { years (CT) }\end{array}$ & $\begin{array}{l}\text { No } \\
\text { Annually for } 3 \text { years } \\
\text { (high risk of recurrence) }\end{array}$ & $\begin{array}{l}\text { Annually for } 5 \text { years } \\
\text { With suspicion }\end{array}$ \\
\hline $\begin{array}{l}\text { Liver } \\
\text { sonography }\end{array}$ & $\begin{array}{l}6 \text { months after surgery then } \\
\text { annually up to } 5 \text { years }\end{array}$ & No & $\begin{array}{l}\text { Every } 6 \text { months for } 3 \text { years then } \\
\text { annually for } 2 \text { years }\end{array}$ \\
\hline Abdominal CT & Annually for 5 years & $\begin{array}{l}\text { Annually for } 3 \text { years } \\
\text { (high risk of recurrence) }\end{array}$ & With suspicion \\
\hline Colonoscopy & Annually for 3 years & $\begin{array}{l}3 \text { years after surgery then } \\
\text { every } 5 \text { years }\end{array}$ & 1 years after surgery then every 3 years \\
\hline
\end{tabular}

${ }^{1}$ Basically for patients with stage III, flexible in patients with lower stage disease.

tients with psychological support, and to evaluate the impact of new therapeutic approaches. However, postoperative follow-up may sometimes be based on a not completely scientific background, including 'health politics', 'national standards' or 'class requirements', namely providing the maximum care possible for patients to avoid being accused of guilt associated with an incurable non-diagnosed recurrence. As a result, Japanese doctors tend to perform intensive follow-up based on national standards. The guidelines of, for example, the JSCCR, the American Society Clinical Oncology and the European Society Medical Oncology confirm these considerations even if these societies all agree on some of the elements while disagreeing on many others regarding performance of an appropriate follow-up (table 5) [17].

\section{Conclusions}

In surgical treatment for colon cancer, a colonic resection with a D3 lymph node dissection is widely accepted as the treatment of choice in Japan. A D3 lymphadenectomy contributes to both local control of disease as well as accurate staging without increasing surgical stress, including operation time and blood loss, in comparison to a D2 lymphadenectomy. This may be related to the fact that Japanese patients tend to have a lower body mass index than Western patients. To date, we have obtained a favorable outcome for the patients with potentially curable colon cancer by means of surgical treatment. However, the prognosis for patients with stage IV disease still remains poor. Multimodal treatment for liver/lung metastases is now being developed and recent systemic chemotherapy trials have demonstrated promising results [7, 18]. Any further improvements in survival rates will depend on both identifying patients earlier in order to surgically treat them in a more timely manner as well as in developing new and effective treatment modalities in the future [19-21].

References

1 Japanese Society for Cancer of the Colon and Rectum: Multi-Institutional Registry of Large Bowel Cancer in Japan. Vol 24: Cases Treated in 1998. Tochigi, Registry Committee, 2003.

2 Wakai K, Hirose K, Ito K, et al: Dietary risk factors for colon and rectal cancers: a comparative case-control study. J Epidemiol 2006;16:125-135.

3 Corman ML: Colon and Rectal Surgery, ed 5. Philadelphia, Lippincott Williams \& Wilkins, 2005, pp 804-856.

4 Japanese Society for Cancer of the Colon and Rectum: General Rules for Clinical and Pathological Studies on Cancer of the Colon, Rectum, and Anus, ed 7 (in Japanese). Tokyo, Kanehara Shuppan, 2006. 
5 Japanese Society for Cancer of the Colon and Rectum: The Guidelines for Therapy of Colorectal Cancer (in Japanese). Tokyo, Kanehara Shuppan, 2005.

6 O'Connell MJ, Laurie JA, Kahn M, et al: Prospectively randomized trial of postoperative adjuvant chemotherapy in patients with high-risk colon cancer. J Clin Oncol 1998;16: 295-300.

7 Goyle S, Maraveyas A: Chemotherapy for colorectal cancer. Dig Surg 2005;22:401414.

8 Monga DK, O’Connell MJ: Surgical adjuvant therapy for colorectal cancer: current approaches and future directions. Ann Surg Oncol 2006;13:1021-1034.

$>9$ Sasson AR, Sigurdson ER: Surgical treatment of liver metastases. Semin Oncol 2002; 29:107-118.

10 Martin LW, Warren RS: Current management of colorectal liver metastases. Surg Oncol Clin North Am 2000;9:853-876.
11 Penna C, Nordlinger B: Surgery and local treatments of liver metastases from colorectal cancer: how to improve results. Scand J Surg 2003;92:90-96.

12 Kato T, Yasui K, Hirai T, et al: Therapeutic results for hepatic metastasis of colorectal cancer with special reference to effectiveness of hepatectomy. Dis Colon Rectum 2003; 46(suppl):S22-S31.

13 McCormack PM, Burt ME, Bains MS, et al: Lung resection of colorectal metastases. 10 year results. Arch Surg 1992;127:1403-1406.

14 Ike H, Shimada H, Ohki S, et al: Results of aggressive resection of lung metastases from colorectal carcinoma detected by intensive follow-up. Dis Colon Rectum 2002;45:468475.

15 Saito Y, Omiya H, Kohno K, et al: Pulmonary metastasectomy for 165 patients with colorectal carcinoma: a prognostic assessment. Thorac Cardiovasc Surg 2002;124:10071013
16 Kitano S, Kitajima M, Konishi F, et al: A multicenter study on laparoscopic surgery for colorectal cancer in Japan. Surg Endosc 2006;20:1348-1352.

17 Destri GL, Cataldo AD, Puleo S: Colorectal cancer follow-up: useful or useless? Surg Oncol 2006; 15:1-12.

18 Saunders M, Iveson T: Management of advanced colorectal cancer: state of art. $\mathrm{Br} \mathrm{J}$ Cancer 2006;95:131-138.

19 Khan S, Tan YM, John A, et al: An audit of fusion CT-PET in the management of colorectal liver metastases. Eur J Surg Oncol 2006;32:564-567.

20 Esteves FP, Schuster DM, Halker RK: Gastrointestinal tract malignancies and positron emission tomography: an overview. Semin Nucl Med 2006;36:169-181.

21 Gasparini G, Longo R, Torino F, et al: Tailored therapy of colorectal cancer: results, challenges and future directions. Cancer J 2005;11:175-188. 